\title{
Oral Mucosal Conditions in Acute Leukemia- A Clinical, Nutritional and Serologic Analysis
}

Lilly Esquivel-Pedraza, DDS, MSc ${ }^{1}$, María del Pilar Milke-García, $\mathrm{PhD}^{2}$, Renata Lucrecia Rivera-Flores, $\mathrm{PhD}^{2}$, Adriana Rosas-López ${ }^{3}$, Silvia Méndez-Flores, MD, MSc, PhD ${ }^{1}$, Marcela Saeb-Lima, MD ${ }^{4}$, Carolina Rodríguez-Padilla ${ }^{5}$, Judith Domínguez-Cherit, MD ${ }^{1}$, Gloria Vizcaíno, $\mathrm{MD}^{6}$, Alba Cicero-Casarrubias, MD, MSc ${ }^{1}$, Ana L. Ruelas-Villavicencio, $\mathrm{MD}, \mathrm{MSc}^{1}$, Laura Fernández-Cuevas, $\mathrm{DDS}^{7^{*}}$

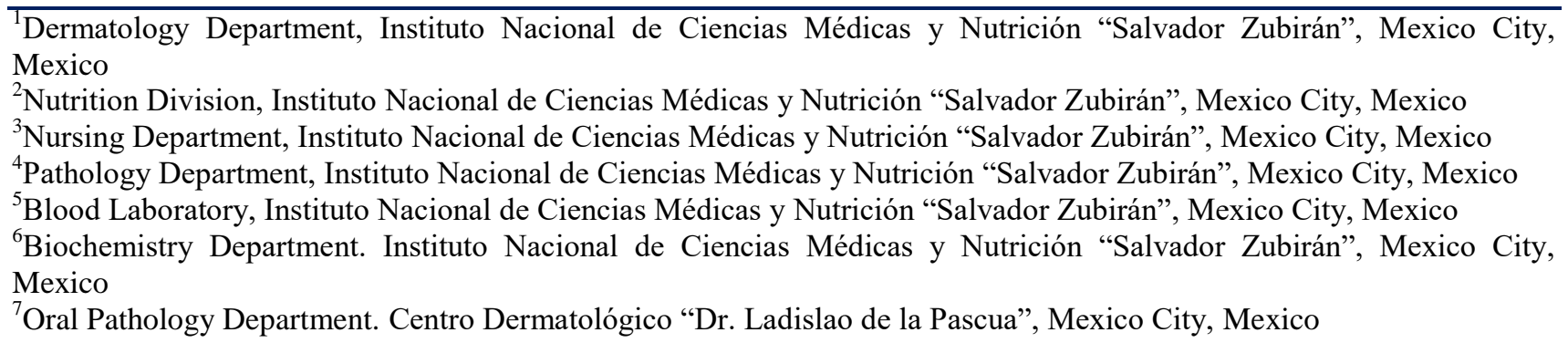

*Corresponding Author: Laura Fernández-Cuevas

Oral Pathology Department. Centro Dermatológico "Dr. Ladislao de la Pascua”, Mexico City, Mexico

\author{
Article History \\ Received: 14.12.2021 \\ Accepted: 22.01 .2022 \\ Published: 27.01.2022
}

\begin{abstract}
A cross-sectional pilot study was conducted in acute leukemia adult patients in order to characterize oral mucosal conditions in acute leukemia, and to analyze their association with certain clinical, nutritional and laboratory parameters. Oral evaluation was performed. Epidemiologic, clinical and laboratory data were considered. Statistical analysis included non-parametric tests and multivariate analysis. A total of 30 patients (60\% males) were included; median age of 39 (range 17-62) years old. The median percentage of caloric intake adequacy was 96.8\% (range 21.8-205.7\%), and the median ideal weight was $117.9 \%$ (range $88.2-162.9 \%$ ). The most common oral mucosal findings were pallor and furred tongue. Leukoedema was seen only in patients $<30$ years old $[\mathrm{OR}=1.9(\mathrm{CI}=1.1-3.1) ; p=0.003]$; more cases of fissured tongue [OR=17.1 $(\mathrm{CI}=1.8-163.8) ; p=0.005]$ were seen in subjects $>30$ years old. Exfoliative cheilitis was more frequent in females $[\mathrm{OR}=2.7$ $(\mathrm{CI}=1.2-6.1) ; p=0.02]$ and in patients with high $\beta$-carotene concentrations $[\mathrm{Md}=94.5$ vs $57.0 \mu \mathrm{g} / \mathrm{dl} ;(p=0.01)]$. Higher rates of diffuse hyperpigmentation were seen $(p<0.05)$ in patients having low vitamin $\mathrm{B}_{12}[\mathrm{Me}=240 \mathrm{vs} 626 \mathrm{pg} / \mathrm{ml}]$ and folic acid concentrations $[\mathrm{Md}=5.8$ vs $8.5 \mathrm{ng} / \mathrm{ml}]$; Geographic tongue was found among patients with low serum albumin $[\mathrm{Md}=2.7 v s 3.5$ $\mathrm{g} / \mathrm{dl} ;(p=0.006)]$ and folic acid $[\mathrm{Md}=7.9$ vs $11.6 \mathrm{ng} / \mathrm{mL} ;(p=0.02)]$. Furred tongue was more frequent in patients with low hemoglobin concentration $[\mathrm{Md}=7.2$ vs $8.5 \mathrm{~g} / \mathrm{dl} ;(p=0.01)]$ and poor oral hygiene $[\mathrm{Md}=1.1$ vs $0.7 ;(\mathrm{p}=0.04)]$. Nutritional depletion was more frequently observed among patients with indentation $(p=0.04)$ and geographic tongue $(p=0.03)]$. Age, gender and certain micronutrient deficiencies were significantly associated to specific oral mucosal findings in acute leukemia.
\end{abstract}

Keywords: Mouth diseases, leukemia, vitamin $\mathrm{B}_{12}$, folic acid, $\beta$-carotene.

\section{INTRODUCTION}

Acute leukemia (AL) is a type of blood cancer, that comes on quickly and is fast growing; broadly classified as either acute myeloid leukemia (AML) or acute lymphoblastic leukemia (ALL) [1,2]. AL is characterized by a spectrum of clinical manifestations [3,4]. The mouth mucosa in leukemia patients is usually affected by the disease and during its treatment, leading to morbidity and an inferior quality of life for the patients [5-7].

The prevalence of oral mucosal lesions or conditions (OML) in AL patients has been underestimated. Most of

Copyright (C) 2022 The Author(s): This is an open-access article distributed under the terms of the Creative Commons Attribution 4.0 International License (CC BY-NC 4.0) which permits unrestricted use, distribution, and reproduction in any medium for non-commercial use provided the original author and source are credited. 
the studies related to the frequency of oral mucosa lesions in these patients usually focus on the stomatological complications that develop during the oncological treatment; however, there are currently few studies dealing with lesions previous to therapy in this set of patients. Also, the correlation of nutritional aspects and the presence of oral mucosal lesions have been scarcely studied in such patients. Thus, the objective of this research was to describe the clinical spectrum of oral mucosal conditions and its relationship with certain epidemiological, clinical and laboratory parameters in AL patients, attending at the Instituto Nacional de Ciencias Médicas y Nutrición "Salvador Zubirán" (INCMNSZ) in Mexico City.

\section{Material ANd Methods}

A cross-sectional pilot study was performed in patients with recent diagnosis of ALL or AML attending at the INCMNSZ during a two year period, in order to determine the prevalence of OML in AL previous to therapy, as well as to correlate particularly those OML with some clinical and laboratory parameters.

Inclusion criteria to the study were subjects $>18$ years old with a confirmed diagnosis of AL according to international criteria [1], who attended the outpatient service of the Hematology Department, with no previous oncologic treatment, and were willing to sign the informed consent form. Exclusion criteria included inability for a complete mouth inspection to be performed, HIV-infected patients, pharmacologic immunosuppression for any reason other than leukemia status; as well as patients under vitamin $\mathrm{B}_{12}$ regimen, folic acid, ferrous sulphate or poly-vitamins containing $\mathrm{B}_{12}$ for less than one month previous to oral exam. This study was previously approved by the Research and Ethics Committees of our institution (number CIIBH-10-155).

A systematic oral examination was performed and standardized clinical criteria were used for the diagnosis of mouth diseases. Clinical diagnoses of oral lesions were confirmed by cytology, histopathology or laboratory as required. Smears fixed in alcohol and stained with periodic acid Schiff technique were taken from the dorsum of the tongue of all patients, in order to rule out Candida infection. Also, Papanicolaou-stained smears were routinely taken from oral lesions when herpetic infection was suspected $[8,9]$. A photographic record was obtained from all the oral findings.

Local factors in mouth such as dental, orthodontic or prosthetic cutting edges, daily use of dentures or mouthwash and smoking and alcohol consumption were considered. Smoking was categorized as occasional $(<5$ cigarettes/week), mild ( $>1$ cigarette/day, $<5$ cigarettes/day), moderate (5-19 cigarettes/day), strong ( $>20$ cigarettes/day) or ex-smoker (at least 3 months without smoking). Alcoholism was considered positive (daily ingestion or intoxication at least once weekly), occasional or negative.

Oral hygiene status was also determined according to the simplified oral hygiene index [10]; arbitrarily, an index $\leq 1.0$ was considered as good oral hygiene and an index $>1.0$ was considered as poor oral hygiene. In order to assess mouth pain, the following terms were considered to define loss of oral functionality: no pain or "asymptomatic"; minimum pain or burning sensation as "slight pain", significant pain without interfering on feeding as "moderate pain", and significant pain restraining feeding as "severe pain".

Nutritional status of patients was evaluated by standardized dietitians (RRF, MPMG), through the Subjective Global Assessment described else [11] and patients were classified as "well nourished", "moderately undernourished or suspected undernourishment" and "severely undernourished". The percentage of ideal body weight (IBW) or current weight in kilograms x 100/ideal weight in kilograms was calculated and patients were categorized accordingly: low body weight $<90 \%$ IBW, acceptable weight $90-120 \%$ IBW and overweight $>120 \%$ IBW [12]. Ideal body weight was obtained from the tables developed by the Metropolitan Life Insurance Company in 1983, where body frame, gender and height are considered [11]. Finally, the percentage of adequacy of the individual caloric intake was estimated by dividing the reported typical caloric intake by the estimated caloric requirements. A percentage of adequacy $<90 \%$ was considered unsatisfactory, from 90 to $110 \%$ satisfactory and above $110 \%$ as excessive energy intake.

Other epidemiologic, laboratory and clinical data, including antibiotic or antifungal use 30 days prior to oral exam (obtained from the medical charts), were also considered. Blood workup at oral examination included complete blood count $\left( \pm 15\right.$ days); serum levels of vitamin $B_{12}$, folic acid, and $\beta$-carotenes $( \pm 1$ week)

In order to facilitate registry of lesions some variables were grouped and dichotomous variables were constructed to simplify analysis. Tobacco habit was dichotomized considering the smokers (including ex-smokers) and non-smokers. Oral infectious processes included herpetic lesions, candidosis, warts, hairy leukoplakia, necrotizing ulcerative gingivitis and bacterial infection of dental origin. Oral candidosis was analyzed by type of presentation and as a group, including erythemathous, pseudomembranous and angular cheilitis related to candidosis. Traumatic lesions included erosive or ulcerative traumatic processes, reactive growths and scars. Oral melanoses were analyzed by group and individually, comprising racial or physiologic hyperpigmentation, diffuse hyperpigmentation (including smokers'

(C) South Asian Research Publication, Bangladesh $\quad$ Journal Homepage: www.sarpublication.com 
melanosis), and melanocytic macules. Subjects without a type of OML were considered controls (non-exposed) and those with a type of OML as cases (exposed). Age was categorized in $\geq 30$ years old and $<30$ years old for statistical analysis purposes.

In order to determine associations between OML and the included variables, $X^{2}$ or Fisher's exact tests were used. Kruskal-Wallis or Mann-Whitney's $U$ non parametric tests were used for the comparison of laboratory and nutritional values in patients with and without OML, as deemed appropriate. Also, $\mathrm{X}^{2}$ linear trend test was used for the evaluation of the nutritional status. Odds ratios were calculated at $95 \%$ confidence intervals (CI) and a multivariate analysis was performed. Statistical significance was set at a two-tailed $p \leq 0.05$.

\section{RESULTS}

A total of 30 patients were included; 18(60\%) males and 12(40\%) females. The median age of patients was of 39 (range 17-62) years old. Nineteen patients were diagnosed with ALL (63.3\%) and 11 (36.7\%) with AML. The clinical and laboratory characteristics of patients are described in Tables 1 and 2. The median percentage adequacy of caloric intake was $96.8 \%$ (range $21.8 \%-205.7 \%$ ). The median percentage of IBW was $117.9 \%$ (range $88.2 \%-162.9 \%$ ). According to the subjective global assessment, seventeen patients (56.7\%) had a satisfactory nutritional status, 10 $(33.3 \%)$ had moderate undernourished and three (10.0\%) were severely undernourished.

All patients $(100 \%)$ had OML, being pallor and furred tongue the most common findings. The prevalence of oral findings is described in Table 3. None of the patients reported pain or swallowing problems except for one (3.3\%) with moderate functionality due to a traumatic ulcer.

Leukoedema was only seen in patients younger than 30 years old [OR=1.9 (CI=1.1-3.1); $p=0.003]$; on the contrary, subjects over 30 years old had more cases of fissured tongue [OR=17.1 $(\mathrm{CI}=1.8-163.8) ; p=0.005]$ in comparison with younger patients. Females had a higher frequency of exfoliative cheilitis $[\mathrm{OR}=2.7(\mathrm{CI}=1.2-6.1) ; p=0.02]$ than males.

Low levels of vitamin $\mathrm{B}_{12}[\mathrm{Md}=240$ vs $626 \mathrm{pg} / \mathrm{ml} ;(p=0.002)]$ and folic acid [Md 5.8 vs $\left.8.5 \mathrm{ng} / \mathrm{ml} ;(p=0.038)\right]$ were seen in patients with oral diffuse hyperpigmentation. A greater risk for this type of hyperpigmentation was observed in patients with oral candidosis $(\mathrm{OR}=3.7$; $\mathrm{IC}=0.6-23)$; however, this was not statistically significant $(p=0.07)$. Also, higher rates of oral melanosis were seen in users of oral rinses [OR=8.5 ( $\mathrm{IC}=1.1-63.9) ; p=0.04]$ than in their counterparts. Oral candidosis was more frequently observed in tobacco smokers [OR=6.7 (IC=1.2-35.7); $p=0.03]$ than in non-smokers.

Patients in whom geographic tongue was found presented lower levels of albumin $[\mathrm{Md}=2.7$ vs $3.5 \mathrm{~g} / \mathrm{dl}$; $(p=0.006)]$ and folic acid $[\mathrm{Md}=7.9$ vs $11.6 \mathrm{ng} / \mathrm{ml} ;(p=0.02)]$ than their counterparts; also, furred tongue was more frequently seen in patients with low levels of hemoglobin $[\mathrm{Md}=7.2 \mathrm{vs} 8.5 \mathrm{~g} / \mathrm{dl} ;(p=0.01)]$ and a poor oral hygiene index $[\mathrm{Md}=1.1 \mathrm{vs} 0.7 ;(p=0.04)]$. Furthermore, high levels of $\beta$-carotene were related to exfoliative cheilitis $[\mathrm{Md}=94.5$ vs 57.0 $\mu \mathrm{g} / \mathrm{dl} ;(p=0.01)]$. These associations remained unchanged after adjusting for confounding factors.

A greater number of mucosal indentations $(p=0.04)$ were observed accordingly with a more deteriorated nutritional [in none of the well-nourished, in three of the moderately undernourished (30\%) and in one of the severely undernourished patients (33\%)]; and also more patients with geographical tongue showed undernourishment [none of the well-nourished, two of the moderately undernourished (20\%) and one of the severely malnourished $(33 \%),(p=0.03)]$.

The OML did not show any other relevant relationship according to gender, type of leukemia or other laboratory tests.

Table 1: Epidemiological and clinical characteristics of patients with acute leukemia

\begin{tabular}{|l|l|l|}
\hline Characteristics & n & (\%/Range) \\
\hline Gender & & \\
\hline Female & 12 & $(40.0)$ \\
\hline Male & 18 & $(60.0)$ \\
\hline Age (years old) & 39 & $(18-62)$ \\
\hline Type of acute leukemia & & \\
\hline Myeloid & 11 & $(36.7)$ \\
\hline Lymphocytic - B & 19 & $(63.3)$ \\
\hline Comorbidity & & \\
\hline Diabetes mellitus & 2 & $(6.7)$ \\
\hline Hypertension & 1 & $(3.3)$ \\
\hline
\end{tabular}

(C) South Asian Research Publication, Bangladesh 


\begin{tabular}{|l|l|l|}
\hline Characteristics & $\mathbf{n}$ & $(\% /$ Range $)$ \\
\hline Mixed collagen tissue disease & 1 & $(3.3)$ \\
\hline Deep venous thrombosis & 1 & $(3.3)$ \\
\hline Second malignancy & 1 & $(3.3)$ \\
\hline Smoking habit $(\mathrm{n}=28)$ & & \\
\hline Negative & 15 & $(53.6)$ \\
\hline Ocassional & 2 & $(7.1)$ \\
Moderate & 2 & $(7.1)$ \\
\hline Ex-smoker & 9 & $(32.1)$ \\
\hline Alcohol habit $(\mathrm{n}=28)$ & & \\
\hline Negative & 10 & $(35.7)$ \\
\hline Ocassional & 15 & $(53.6)$ \\
\hline Positive & 3 & $(10.7)$ \\
\hline Oral rinses use $(\mathrm{n}=27)$ & 6 & $(22.0)$ \\
\hline Presence of oral prosthesis & & \\
\hline Fixed & 4 & $(13.3)$ \\
\hline Removable & 2 & $(6.7)$ \\
\hline Cutting edges $(\mathrm{n}=25)$ & 12 & $(48.0)$ \\
\hline Dental status $*(\mathrm{Md})$ & & \\
\hline Decayed & 10.5 & $(1-16)$ \\
\hline Missing & 0 & $(0-17)$ \\
\hline Filled & 0 & $(0-17)$ \\
\hline Oral hygiene $* *(\mathrm{Md})$ & 0.915 & $(0.17-2.3)$ \\
\hline
\end{tabular}

*Decayed, missing, and filled teeth (DMFT) index **Simplified Oral Hygiene Index

Table 2: Laboratory characteristics in patients with acute leukemia

\begin{tabular}{|l|l|l|}
\hline Laboratory values & Md & (Range) \\
\hline Hemoglobin $(\mathrm{g} / \mathrm{dL})$ & 8.3 & $(3.5-13.1)$ \\
\hline Platelets $(\mathrm{K} / \mathrm{uL})$ & 22.0 & $(9.0-287.0)$ \\
\hline Leukocytes $(\mathrm{K} / \mu \mathrm{L})$ & 9.1 & $(0.6-125.0)$ \\
\hline Lymphocytes $(\mathrm{K} / \mu \mathrm{L})$ & 48.4 & $(3.0-97.2)$ \\
\hline Neutrophils $(\mathrm{cells} / \mu \mathrm{L})$ & 842 & $(0-53280)$ \\
\hline Albumin $(\mathrm{g} / \mathrm{dL})$ & 3.5 & $(2.5-4.7)$ \\
\hline Folic acid $(\mathrm{ng} / \mathrm{mL})$ & 8.1 & $(4.1-18.5)$ \\
\hline Vitamin $\mathrm{B}_{12}(\mathrm{pg} / \mathrm{mL})$ & 513.5 & $(100.0-8806)$ \\
\hline$\beta$-carotene $(\mu \mathrm{g} / \mathrm{dL}) *$ & 71.0 & $(37.0-163.0)$ \\
\hline \multicolumn{2}{|c|}{$*(\mathrm{n}=15$ patients $)$}
\end{tabular}

Table 3: Frequency of oral mucosal lesions in 30 patients with acute leukemia

\begin{tabular}{|l|l|l|}
\hline Oral lesion & $\mathbf{n}$ & $\mathbf{( \% )}$ \\
\hline Paleness & 22 & $(73.3)$ \\
\hline Furred tongue & 20 & $(66.7)$ \\
\hline Infectious processCandidosis & & \\
\hline Erythematous & 15 & $(50.0)$ \\
\hline Pseudomembranous & 3 & $(10.0)$ \\
\hline Herpetic lesions & 9 & $(30.0)$ \\
\hline Hairy leukoplakia & 1 & $(3.3)$ \\
\hline Necrotizing ulcerative gingivitis & 1 & $(3.3)$ \\
\hline Focal epithelial hyperplasia & 1 & $(3.3)$ \\
\hline Bacterial infection * & 1 & $(3.3)$ \\
\hline Melanosis & & \\
\hline Racial hypermelanosis & 9 & $(30.0)$ \\
\hline Difusse hypermelanosis & 6 & $(20.0)$ \\
\hline Melanotic macule & 3 & $(10.0)$ \\
\hline Hemorragic lesions & 14 & $(46.7)$ \\
\hline Exfoliative cheilitis & 14 & $(46.7)$ \\
\hline Fissured tongue & 11 & $(36.7)$ \\
\hline
\end{tabular}




\begin{tabular}{|l|l|l|}
\hline Oral lesion & $\mathbf{n}$ & $\mathbf{( \% )}$ \\
\hline Hairy tongue & 10 & $(33.3)$ \\
\hline Traumatic lesions** & 10 & $(33.3)$ \\
\hline Atrophic glossitis & 8 & $(26.7)$ \\
\hline Leukoedema & 6 & $(20.0)$ \\
\hline Xerostomia & 5 & $(16.7)$ \\
\hline Fordyce's spots & 4 & $(13.3)$ \\
\hline Tongue indentation & 4 & $(13.3)$ \\
\hline Geographic tongue & 3 & $(10.0)$ \\
\hline Varix & 3 & $(10.0)$ \\
\hline Others *** $*$ Dental origin. & 3 & $(10.0)$ \\
\hline \multicolumn{3}{|c}{} \\
lude erosions (6), ulcers (3), one reactive lesion (fibrous hyperplasia) \\
a scar, an erythemathous macule and a toothpaste related desquamation
\end{tabular}

\section{DiscuSSION}

Most of the studies related to OML in AL patients focus on their development while leukemia patients are being treated, therefore papers describing the OML before the oncologic treatments are scarce. In this manuscript, we present the prevalence of oral findings and clinical, epidemiologic, nutritional status and laboratory characteristics of an exclusive group of AL subjects at diagnosis who attended our institution. The study was carried out by a multidisciplinary team (specialists in Oral Pathology, Nutrition and Hematology) in a tertiary care center in patients without social security [13] in Mexico City.

The high frequency and most common OML in our patients (pallor, furred tongue and candidosis) mainly correspond to the expected indirect effects of myelosuppression and immunosuppression secondary to the disease, both previously described in the literature [14].

Our results highlight the high prevalence of oral candidosis, mainly of the erythematous type. The range of global candidosis described for this type of patients widely vary between 6\% and 74\% [15] depending on the method used for its detection. These contrasting variations could be related not only to differences in the methodology, but the characteristics of the studied population, such as degree of immunosuppression or oral hygiene status [14]. Also, erythematous candidosis has been scarcely referred in oncologic studies and the general lack of awareness on behalf of the health professionals could be the main reason for this variation. It is possible that this clinical presentation of oral candidosis may be still unrecognized and therefore its underestimation, despite its high prevalence, similar to what has been observed in other immunosuppressed subjects [16]. The high prevalence reported in our study remarks the importance of defining immediate care to control this infectious disease in this set of patients and of generating measures that may prevent the development of other forms of candidosis such as the pseudomembranous ensuing the oncologic treatment.

The oral analysis focusing on the nutritional status has been dimly studied in patients with AL; patients with moderate and severe undernutrition have a greater risk of adverse events related to the antineoplastic treatment and are less responsive and tolerance to it [17, 18]; the quality of life and survival are also diminished [19]. More than 50\% of our patients had a satisfactory nutritional status; however, the rest of them were moderately or severely undernourished, a fact that by itself is a marker of bad prognosis for the tolerance to antineoplastic management, as reported elsewhere [1719]

The percentages of IBW and adequacy of the caloric intake in our patients were both considered satisfactory (117.9\% and $96.8 \%$, respectively). However, the subjective global assessment detected a high percentage of patients with moderate undernutrition (43\%). Nevertheless, considering these adequacy indicators, some OML could be observed; some of these could even be associated to certain nutritional deficiencies. This might be explained by the fact the nutritional status is not only defined in terms of weight or food intake, but also in terms of a specific blood analysis looking for nutritional deficiencies that could therefore be relevant in patients with AL.

The finding of fissured tongue among the oldest patients, together with the high frequency of oral candidosis in tobacco smokers, and the leukoedema found mainly in the younger patients were expected associations, long-time described in many previous studies [20-24]. However, among our results some findings that have barely been described could be identified, such as furred tongue among patients with low serum hemoglobin concentration or a deficient oral hygiene. Even thought, although the detection of furred tongue is common, studies relating this finding to different factors that enable its presence are few; furthermore, its clinical significance is controversial [25, 26]. Despite the 
historical association of this clinical entity with a pathological state, it may also be observed even in healthy children [26]. Fever, respiratory tract infection and oral factors such as tobacco smoking [25] or mouth mucosa wounds have etiologically been related to the development of furred tongue. In our patients, adynamia secondary to low serum iron, and no only the conditions related to the underlying disease on these patients, may have contributed to an inadequate oral hygiene, followed by the formation of furred plaques; however, other factors such as the decrease in the mechanical strength, neurological impairment [5], dental occlusion, pharyngotonsillitis episodes and recent vomiting, among other factors that where not assessed in our study, could have modified the presence of this condition.

A prevalence of $1-2 \%$ of geographical tongue together with a $5.1 \%$ increase in patients with hematological derangements has been described [27]. The concordance of geographical tongue with multiple factors such as age; immunological, genetic, allergic and atopic factors; emotional stress and tobacco smoke, as well as the presence of fissured tongue, candidosis or hormonal disorders, psoriasis, diabetes mellitus, the burning mouth syndrome or Down syndrome has widely been reported [28-30]; and more specifically, it has also been related to zinc deficiency [28]. Our findings emphasize the close relationship between the geographical tongue and the low concentrations of folates and albumin. Patients receiving chemotherapy usually manifest vitamin deficiencies, mainly of the B complex, including folic acid [31]. Furthermore, hypoalbuminemia has been considered a death and early death predictor in other type of patients [32]. Therefore, the indicators found in our study not only may be associated to a nutritional depletion in our patients before receiving oncological treatment, but may also be related to the clinical course of the disease. The findings from the subjective global assessment discussed above also add up to this fact.

Another interesting finding was the difference in prevalence of exfoliative cheilitis due to gender and its relationship with the high concentrations of $\beta$-carotenes, regardless of the presence of xerostomy. Oral mucosa scaling, including exfoliative cheilitis, has been described in patients using retinoids as exfoliator for the dermatological control of acne [33-35]. However, the association of high levels of vitamin A and exfoliative cheilitis had not been previously described in a specific set of patients, such as our subjects with leukemia.

The population included in our study was predominantly mestizo (half-caste); thus, the presence of different types of hyper melanosis was an expected finding, although this feature has rarely been described in patients with leukemia. Our results highlight the relationship between general melanosis and the routine use of antiseptics, suggesting the possibility of an irritative role, specifically in the race of our patients. The association between diffuse hyperpigmentation and the low serum vitamin $\mathrm{B}_{12}$ and folic acid concentrations could be partially related to a mucosal post-inflammatory damage as a consequence of chronic candidosis, despite our non-statistically significant results $(\mathrm{OR}=3.7 ; \mathrm{IC}=0.6-23, p=0.07)$. However, more follow-up studies are required in order to confirm this hypothesis.

\section{CONCLUSION}

Patients with AL frequently display OML that may be secondary to this disease and that should be readily identified and controlled before being submitted to an antineoplastic therapy, because the current treatments are still known to contribute to worsening the patient [36].

\section{ACKNOWLEDGMENTS}

All authors would like to thank Dr. Erick Crespo-Solís for all his invaluable help, and dietitian Jesús Antonio Hernández-Morales, for his technical assistance.

Financial disclosure: This research did not receive any specific grant from funding agencies in the public, commercial, or not-for-profit sectors.

\section{Conflict of interest: None reported}

\section{REFERENCES}

1. Vardiman, J. W., Thiele, J., Arber, D. A., Brunning, R. D., Borowitz, M. J., Porwit, A., ... \& Bloomfield, C. D. (2009). The 2008 revision of the World Health Organization (WHO) classification of myeloid neoplasms and acute leukemia: rationale and important changes. Blood, The Journal of the American Society of Hematology, 114(5), 937951.

2. Estey, E. (2014). CME information: acute myeloid leukemia: 2014 update on risk-stratification and management. American Journal Hematology, 89(11), 1063-1081. Doi: 10.1002/ajh.23834.

3. Deliverska, E. G., \& Krasteva, A. (2013). Oral signs of leukemia and dental management-literature data and case report. Journal of IMAB, 19(4), 388-391. Doi: 10.5272/jimab.2013194.388 
4. Inaba, H., Greaves, M., \& Mullighan, C. G. (2014). Acute lymphoblastic leukaemia. Lancet, 381(9881), $1943-1955$. Doi: 10.1016/S0140-6736(12)62187-4.

5. Adeyemo, T. A., Adeyemo, W. L., Adediran, A., Akinbami, A. A., \& Akanmu, A. S. (2011). Orofacial manifestation of hematological disorders: Hemato-oncologic and immuno-deficiency disorders. Indian Journal of Dental Research, 22(5), 688-697. Doi: 10.4103/0970-9290.93458.

6. Xavier, A. M., Hegde, A. M. (2010). Preventive protocols and oral management in childhood leukemia-the pediatric specialist's role. Asian Pacific Journal of Cancer Prevention, 11(1), 39-43.

7. Belfield, P. M., \& Dwyer, A. A. (2004). Oral complications of childhood cancer and its treatment: current best practice. European Journal of Cancer, 40(7), 1035-1041. Doi: 10.1016/j.ejca.2003.09.041

8. Ellepola, A. N. B., \& Samaranayake, L. P. (2000). Oral candidal infections and antimycotics. Critical Reviews in Oral Biology \& Medicine, 11(2), 172-198. Doi: 10.1177/10454411000110020301.

9. Barrett, A. P., Buckley, D. J., Greenberg, M. L., \& Earl, M. J. (1986). The value of exfoliative cytology in the diagnosis of oral herpes simplex infection in immunosuppressed patients. Oral Surgery Oral Medicine and Oral Pathology, 62(2), 175-178. Doi:https://doi.org/10.1016/0030-4220(86)90041-1

10. Greene, J. C., \& Vermillion, J. R. (1964). The simplified oral hygiene index. Journal of the American Dental Association, 68(1), 7-13. https://doi.org/10.14219/jada.archive.1964.0034.

11. Detsky, A. S., Baker, J. P., Johnston, N., Whittaker, S., Mendelson, R. A., \& Jeejeebhoy, K. N. (1987). What is subjective global assessment of nutritional status?. Journal of parenteral and enteral nutrition, 11(1), 8-13.

12. Seagle, H. M., Strain, G. W., Markis, A., Reeves, R. S., \& American Dietetic Association. (2009). Position of the American dietetic association: weight management. Journal of the American Dietetic Association, 109(2), $330-346$. Doi: 10.1016/j.jada.2008.11.041.

13. Arredondo, A., \& Aviles, R. (2015). Costs and epidemiological changes of chronic diseases: implications and challenges for health systems. PLoS One, 10(3), e0118611. Doi: 10.1371/journal.pone.0118611

14. Javed, F., Utreja, A., Correa, F. O. B., Al-Askar, M., Hudieb, M., Qayyum, F., ... \& Al-Hezaimi, K. (2012). Oral health status in children with acute lymphoblastic leukemia. Critical reviews in oncology/hematology, 83(3), 303309.

15. Bergmann, O. J. (1988). Oral Infections and septicemia in immunocompronmised patients with hematologic malignancies. Journal of Clinical Microbiology, 26(10), 2105-2109. Doi:10.1128/jcm.26.10.2105-2109.1988

16. Cruz, G. D., Lamster, I. B., Begg, M. D., Phelan, J. A., Gorman, J. M., \& El-Sadr, W. (1996). The accurate diagnosis of oral lesions in human immunodeficiency virus infection: Impact on medical staging. Archives of Otolaryngology Head \& Neck Surgery, 122(1), 68-73. Doi: 10.1001/archotol.1996.01890130060010

17. Dewys, W. D., Begg, C., Lavin, P. T., Band, P. R., Bennett, J. M., Bertino, J. R., ... \& Tormey, D. C. (1980). Prognostic effect of weight loss prior tochemotherapy in cancer patients. The American journal of medicine, 69(4), 491-497.

18. Andreyev, H. J. N., Norman, A. R., Oates, J., \& Cunningham, D. (1998). Why do patients with weight loss have a worse outcome when undergoing chemotherapy for gastrointestinal malignancies?. European Journal of Cancer, 34(4), 503-509. Doi: 10.1016/s0959-8049(97)10090-9

19. Ollenschläger, G., Thomas, W., Konkol, K., Diehl, V., \& Roth, E. (1992). Nutritional behaviour and quality of life during oncological polychemotherapy: results of a prospective study on the efficacy of oral nutrition therapy in patients with acute leukaemia. European Journal of Clinical Investigation, 22(8), 5-23. Doi: https://doi.org/10.1111/j.1365-2362.1992.tb01504.x

20. Delaney, J. E. (1995). Periodontal and soft-tissue abnormalities. Dental Clinics of North America, 39(4), 837-850.

21. Darwazeh, A. M. G., \& Almelaih, A. A. (2012). Tongue lesions in a Jordanian population. Prevalence, symptoms, subject's knowledge and treatment provided. Journal of Clinical and Experimental Dentistry, 4(5), e286-e291. Doi:10.4317/medoral.17098

22. Vellappally, S., Fiala, Z., Šmejkalová, J., Jacob, V., \& Somanathan, R. (2007). Smoking related systemic and oral diseases. Acta Medica (Hradec Králové), 50(3), 161-166.

23. Reibel, J. (2003). Tobacco and oral diseases. Medical Principles and Practice, 12(Suppl 1), 22-32. Doi: https://doi.org/10.1159/000069845

24. Jahanbani, J., Sandvik, L., Lyberg, T., \& Ahlfors, E. (2009). Evaluation of oral mucosal lesions in 598 referred Iranian patients. Open Dentistry Journal, 3, 42-47. Doi: 10.2174/1874210600903010042

25. Loudon, L. (1956). Significance of a furred tongue. British Medical Journal, 1(4957), 18-20. Doi: https://doi.org/10.1136/bmj.1.4957.18

26. Gans, B. (1954). The fallacy of the furred tongue. British Medical Journal, 2(4897), 1146-1147. Doi: https://doi.org/10.1136/bmj.2.4897.1146

27. Miroglu, O., Goregen, M., Akgul, H. M., \& Acemoglu, H. (2009). The prevalence and risk factors associated with benign migratory glossitis lesions in 7619 Turkish dental outpatients. Oral Surgery Oral Medicine Oral Pathology Oral Radiology and Endodontics, 107(2), e29-e33. Doi: 10.1016/j.tripleo.2008.10.015. 
28. Huamei, Y., Yu, Z., Xin, Z., Ga, L., \& Qianming, C. (2015). Research progress on the risk factors of geographic tongue. Hua Xi Kou Qiang Yi Xue Za Zhi (West China Journal Stomatology), 33(1), 93-97. Doi: 10.7518/hxkq.2015.01.021

29. Alikhani, M., Khalighinejad, N., Ghalaiani, P., Khaleghi, M., Askari, E., \& Gorsky, M. (2014). Immunologic and psychologic parameters associated with geographic tongue. Oral Surgery Oral Medicine Oral Pathology and Oral Radiology, 118(1), 68-71. Doi: 10.1016/j.0ooo.2014.03.007.

30. Wu, Y., Wu, Y., Wang, Y., Chang, Y., Chang, J., Chen, H., \& Sun, A. (2016) Hematinic deficiencies and anemia statuses in recurrent aphthous stomatitis patients with or without atrophic glossitis. Journal of the Formosan Medical Association, 115(12), 1061-1068. Doi:10.1016 / j.jfma.2016.10.007

31. Dreizen, S., McCredie, K. B., Keating, M. J., \& Anderson, B. S. (1990) Nutritional deficiencies in patients receiving cancer chemotherapy. Postgraduate Medicine, 87(1), 163-170. Doi: 10.1080/00325481.1990.11704531

32. Corcoran, A. T., Kaffenberger, S. D., Clark, P. E., Walton, J., Handorf, E., Piotrowski, Z., ... \& Kutikov, A. (2015). Hypoalbuminaemia is associated with mortality in patients undergoing cytoreductive nephrectomy. BJU International, 116(3), 351-357. Doi: 10.1111/bju.12897.

33. Kobayashi, H., \& Tagami, H. (2004). Functional properties of the surface of the vermilion border of the lips are distinct from those of the facial skin. British Journal of Dermatology, 150(3), 563-567. Doi: 10.1046/j.13652133.2003.05741.x.

34. Graham, B. S., \& Barrett, T. L. (1999). Mucosal denudation of the lips from isotretinoin therapy. Archives of Dermatology, 135(3), 349-350. Doi:10-1001/pubs.Arch Dermatol.-ISSN-0003-987x-135-3-dlt0399

35. Meigel, W. N. (1997). How safe is oral isotretinoin?. Dermatology, 195(Suppl 1), 22-28, 38-40. Doi: $10.1159 / 000246016$

36. Hijiya, N., \& van der Sluis, I. M. (2016). Asparaginase-associated toxicity in children with acute lymphoblastic leukemia. Leukemia \& Lymphoma, 57(4), 748-757. Doi: 10.3109/10428194.2015.1101098 